\title{
Current Management of Difficult Central Venous Access in Pediatric Patients
}

Wongsakorn Chaochankit, M.D., Surasak Sangkhathat, M.D., Ph.D.

Department of Surgery, Faculty of Medicine, Prince of Songkla University, Hat Yai, Songkhla 90110, Thailand.

Received 28 June 2018 • Revised 10 October 2018 • Accepted 22 October 2018 • Published online 15 January 2019

\section{Abstract:}

The central venous catheter (CVC) has become an integral part of various long term parenteral therapies including chemotherapy and parenteral nutrition. In pediatric patients with a long term CVC, multiple repeated accesses and catheter-related complications may lead to difficulty in reestablishment of a line. Strategies in CVC management in these patients should begin with choosing an appropriate catheter according to its purpose, choosing the right access site and prompt treatment of potential complications, especially catheter-related thrombosis. In patients with severe restriction of the superior vena cava and its tributaries, end-stage central venous access is diagnosed. Management of this situation requires a multidisciplinary team and alternative routes of venous access including access through small collateral veins, or through an unusual vein such as the hepatic vein or a gonadal vein, and/or use of alternative surgical techniques. This article provides a comprehensive review regarding the current approach and surgical options in pediatric patients with end-stage central venous access.

Keywords: catheter-related thrombosis, central venous catheter, end-stage venous access

Contact: Assoc. Prof. Surasak Sangkhathat, M.D., Ph.D.

Department of Surgery, Faculty of Medicine, Prince of Songkla University,

Hat Yai, Songkhla 90110, Thailand.

E-mail:surasak.sa@psu.ac.th
J Health Sci Med Res 2019;37(1):67-80 doi: 10.31584 /jhsmr.201937 www.jhsmr.org 


\section{Introduction}

Central venous access is a necessary tool in providing a route for administration of drugs, fluids and blood product therapy in certain circumstances, including both long term parenteral therapy and critical illnesses. ${ }^{1}$ A central venous catheter (CVC) facilitates the administration of resuscitation fluid, drugs and nutrition directly into large, high-flow veins. ${ }^{2}$ In pediatric patients, the CVC access procedure is often challenging due to anatomical difficulties, particularly small and fragile veins and an abundant amount of subcutaneous fat in infants, which may prohibit a clear surgical approach. ${ }^{3}$ In addition, pediatric patients are less co-operative in surgery and may have psychological trauma if a procedure needs to be repeated. ${ }^{1}$ Maintenance of the device to meet the therapeutic requirements without infectious or mechanical complications is also a challenging issue in cases requiring longterm central venous catheterization, such as those with intestinal failure. ${ }^{4}$ Modern care of venous devices in pediatric cases is best provided by a multidisciplinary care team that includes surgeons, intervention radiologists, pediatricians and nurses. For a surgeon, indications, choices of surgical techniques and vascular access devices, and recognition and management of complications are essential knowledge..$^{5-7}$

This review provides a broad picture of current practice in central venous access in pediatric patients and emphasizes the management of difficult venous access in patients who require long-term catheterization and are at risk of having end-stage central vascular access.

\section{Definition and indications for central venous access in pediatric patients}

Central venous access is defined as placement of an intravenous catheter such that one end of the catheter is laid into a 'venous great vessel' and the other end is exteriorized through the skin or implanted underneath the skin in order to be used for therapeutic administration. The venous great vessels are large bore veins with a high flow rate, such as the superior vena cava, the inferior vena cava, the brachiocephalic veins, and the internal jugular veins. ${ }^{8}$ Therapy administered through the device goes directly into the circulation and is rapidly diluted so that it is less irritable to the vascular wall. In a catheter with an exteriorized part, the point where a catheter passes through the skin is called the 'exit site'. Reasons for central venous access include administration or facilitation of fluid therapy, drugs or nutritional support. ${ }^{9}$

\section{Sites and techniques of central venous access}

Central venous catheters in children are usually inserted through the subclavian, the internal jugular, or the femoral vein. Choice of access in each patient is affected by several factors including venipuncture technique, risk of related mechanical complications, the feasibility of appropriate care of the catheter exit site, and the risk of thrombotic and infective complications. ${ }^{10}$ Modern imaging technology, i.e. ultrasonographic guidance, supports percutaneous puncture as the preferable technique of CVC insertion rather than the conventional venous cutdown (open) technique which has a higher risk of complications. In current practice, the open technique is reserved for access sites in which the target vein is too tortuous or too small to accept a catheter of adequate size. Recent catheter technology allows passing a catheter via the access point at a peripheral vein to the great vein, a technique known as peripherally inserted central venous catheter (PICC).

There are 2 main techniques of passing a catheter into a vein percutaneously, the 'catheter under the sheath' technique and the 'catheter over the wire' technique." The former, known as Seldinger's technique, is used for 
a soft or a small-sized catheter such as a silicone catheter, while the latter uses a relatively hard-tipped catheter made of polyurethane.

The internal jugular veins remain the first-line permanent access site due to a lower risk of procedural and delayed complications compared to other sites. ${ }^{10}$ Although the subclavian veins can be easily accessed percutaneously, they are avoided as a first-line access in long-term catheterization because of a higher rate of venous stenosis and thrombosis compared to the internal jugular veins. When both jugular veins have been occluded, subclavian vein catheterization is the next option. $^{12}$ Access to the venous system in the lower part of body, including femoral veins and their branches, are preferable for short-term use in pediatric cases. However, the lower body sites are prone to contamination from urine and fecal materials, and are avoided if possible for long-term catheterization. (Figure 1 and Table 1)

\section{Types of central venous catheter}

CVCs are categorized into 3 types according to the exteriorized part of the catheter. ${ }^{17}$ (Table 2)

-Non-tunneled catheters are those with an exit site at the skin lying just over the venous access site. Examples of catheters in this group are percutaneous double-lumen or triple-lumen catheters made of polyurethane. A non-tunneled catheter is usually used temporarily as their longevity is usually not longer than a few weeks.

-Tunneled catheters are catheters with an external segment, between the venous puncture site and the skin exit site, placed underneath the subcutaneous plane. The tunneled part may have a Teflon cuff that functions as an anchor that prevents the catheter from dislodgement in long-term implantation. A common example of this type of catheter is the Hickman catheter.

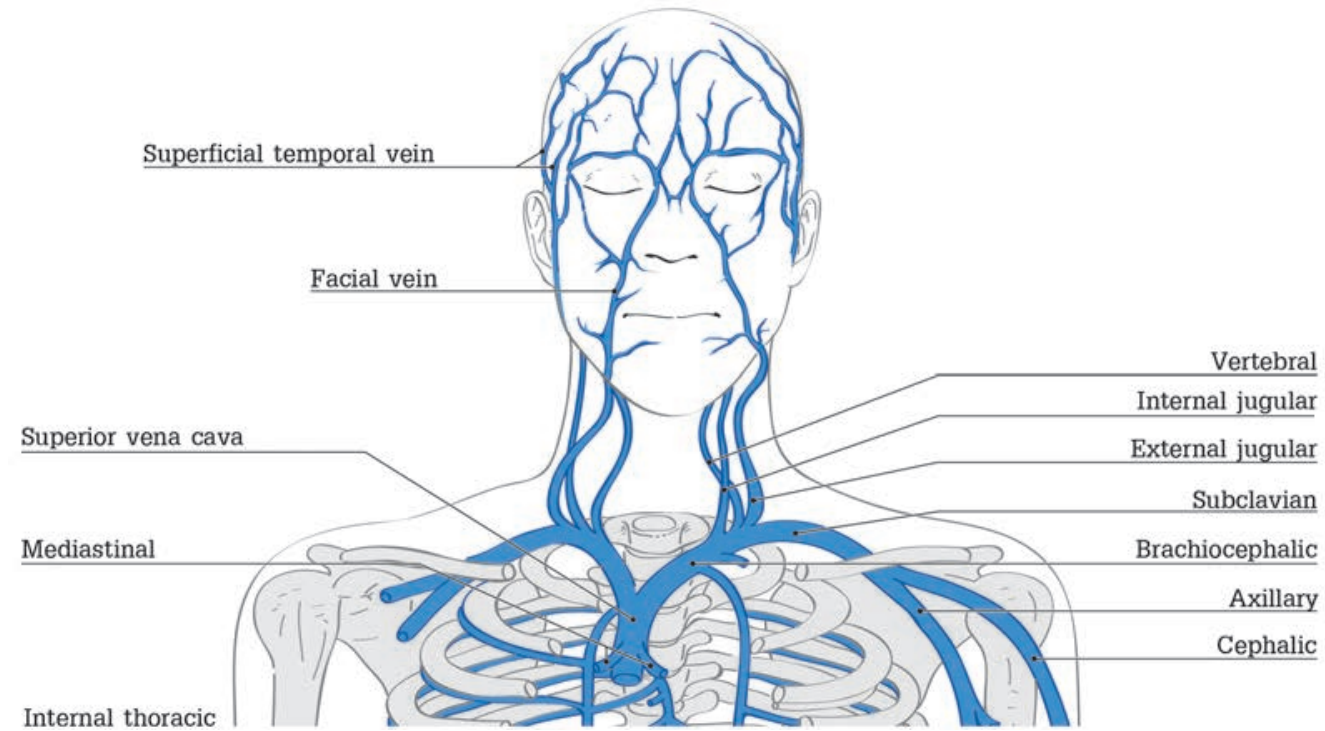

Figure 1 Veins of the thoracic and abdominal regions which can be used for central venous access. ${ }^{16}$ 
Table 1 Routes of insertion for long-term central venous access in children according to termination of the catheter end (see also Figure 1) $)^{2,13-15}$

\begin{tabular}{lll}
\hline SVC & IVC & Right atrium \\
\hline Superficial temporal veins & Femoral veins* & All sites used for SVC and IVC access \\
External jugular veins* & Inferior epigastric veins & Direct right atrial catheterization \\
Internal jugular veins* & Saphenous veins** & \\
Common facial veins & lliac veins & \\
Subclavian veins* & Translumbar & \\
Cephalic veins** $_{\text {Axillary veins }}^{*}$ & Transhepatic & \\
Intercostal veins & & \\
Azygos vein & & \\
\hline
\end{tabular}

${ }^{*}$ Commonly chosen, ${ }^{* *}$ alternative choices, SVC=superior vena cava, IVC=inferior vena cava

Table 2 Indications for central venous catheterization and the choices of device used in pediatric patients ${ }^{8}$

\begin{tabular}{|c|c|}
\hline Purpose of intravenous therapy & Choice of CVC devices \\
\hline $\begin{array}{l}\text { Temporary use } \\
\text {-Provision of resuscitation fluid in emergency situations } \\
\text {-Intravenous venous pressure monitoring } \\
\text {-Plasma exchange, blood exchange or blood transfusion in } \\
\text { neonates or small infants } \\
\text {-Route of drug administration in patients with difficult peri- } \\
\text { pheral vein access (obese infants, very small neonates) }\end{array}$ & $\begin{array}{l}\text { Mostly non-tunneled percutaneous catheter } \\
\text {-Polyvinylchloride vascular sheath } \\
\text {-Single/-/, double/-/(hyphens not correct, not needed) or } \\
\text { triple lumen polyurethane percutaneous catheter } \\
\text {-Umbilical venous catheter }\end{array}$ \\
\hline $\begin{array}{l}\text { Short-term use (a couple of weeks) } \\
\text {-Renal replacement hemodialysis } \\
\text {-Short-term (PN) } \\
\text {-Medium term pharmacotherapy such as antibiotics or anti- } \\
\text { fungal agents }\end{array}$ & $\begin{array}{l}\text { Tunneled or non-tunneled catheter } \\
\text {-Double/-/(as above) or triple lumen percutaneous catheter } \\
\text { (preferred) } \\
\text {-Peripherally inserted central venous catheter } \\
\text {-Tunneled silicone catheter }\end{array}$ \\
\hline $\begin{array}{l}\text { Long-term or permanent use } \\
\text {-Chemotherapy } \\
\text {-Long-term PN in patients with intestinal failure } \\
\text {-Venous access in chronically ill children who require repeated } \\
\text { venous punctures for blood sampling and medication }\end{array}$ & $\begin{array}{l}\text { Tunneled catheter } \\
\text { - Hickman or Broviac type tunneled catheter with sub- } \\
\text { cutaneous cuff } \\
\text {-Port-A-Cath (TIVAD type) }\end{array}$ \\
\hline
\end{tabular}

$C V C=$ central venous catheter, $\mathrm{PN}=$ parenteral nutrition, TIVAD=totally implantable venous access device 
-Totally Implantable Venous Access Device

(TIVAD) refers to a group of catheters in which all parts of the device are implanted within the body. When the venous access part is placed within a great vein, the other end is tunneled beneath the subcutaneous plane and connected to a destination chamber capped with a silicone dome. TIVAD implantation is usually applied when longterm access is required. Access to the chamber system is made by a percutaneous puncture using a specialized non-coring needle such as a Huber needle. The anterior chest wall is the preferred site for placing the subcutaneous chamber of a TIVAD system as the rigid chest wall provides a good place for immobilization of the puncture needle.

\section{Complications of catheter insertion}

A recent study found that the 2 most common complications following a long period of catheterization were thrombosis (1.0-56.0\%) and catheter-related bloodstream infection $(2.4-26.0 \%){ }^{18}$

\section{-Catheter-related blood-stream infections} (CRBSIs)

CRBSIs are defined as bacteremia/fungemia in a patient with an intravascular catheter with at least one positive blood culture obtained from a peripheral vein, together with clinical manifestations of infection, and no apparent source for the bloodstream infection other than the catheter. CRBSIs are deemed to be associated with a central line if the line has been in use during the 48hour period before the development of the bloodstream infection. ${ }^{19}$ CRBSIs can be minimized by strictly following the universal asepsis protocol precautions. ${ }^{20}$ Although studies in pediatric patients are limited, evidence from an adult series showed that Teflon, silicone and polyurethane
(PUR) catheters were associated with lower rates of CRBSIs compared to polyvinyl chloride or polyethylene catheters. ${ }^{20}$ Fortunately, almost all currently available CVCs are made of either PUR or silicone.22

The risk of catheter-related infection can be reduced by using tunneled and TIVAD catheters (proven only in long-term use), antimicrobial coated catheters (proven only in short-term use), single-lumen catheters, using PICC when possible, an appropriate insertion site, ultrasound-guided venipuncture, use of maximal barrier precautions during insertion, proper education and specific training of staff, a policy of adequate hand washing, use of $2.0 \%$ chlorhexidine as a skin antiseptic, appropriate dressing of the exit site, disinfection of hubs, stopcocks and needle-free connectors, and regular change of adminis-tration sets. ${ }^{23-26}$

\section{-Catheter-related thrombosis}

Catheter-related thrombosis remains the most common complication leading to irreversible dysfunction; its incidence is underestimated because it is usually asymptomatic. Three types of catheter-related thrombosis may develop, including a fibrin sheath around the catheter tip, an intraluminal blood clot, and venous thrombosis (Figure 2). ${ }^{27} \mathrm{~A}$ thin fibrin sheath usually develops within 24 hours after catheter placement and may progress to an intraluminal clot. $^{28,29}$ The clot can be related to the development of bacterial biofilm within the catheter (Figure 3). Intraluminal thrombotic occlusion and fibrin sheath formation are common causes of device malfunction, although both of these conditions are minor and can be readily resolved by fibrinolytic agents. Surgical intervention should be considered only after fibrinolytic agents have failed. ${ }^{30,31}$ 

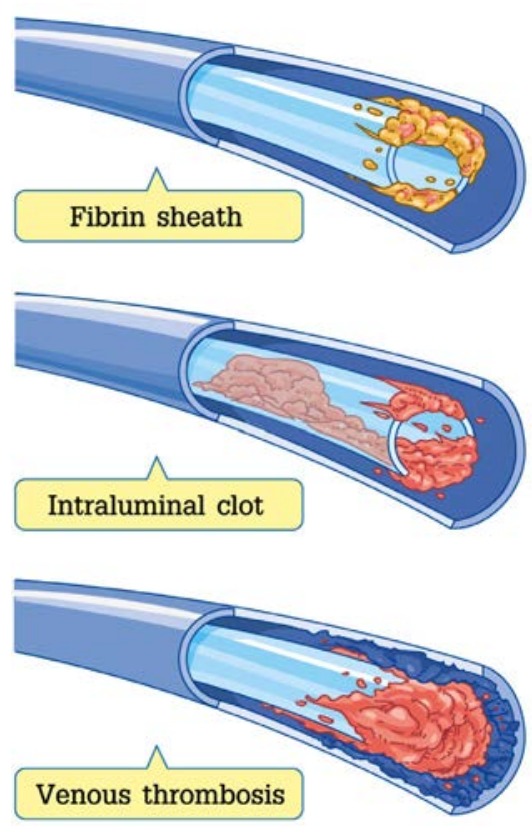

Figure 2 Types of catheter-related thrombosis: fibrin sheath occurred loosely within 24 hours of implantation. An intraluminal clot is a reversible thrombotic condition when venous thrombosis potentially results in permanent luminal compromise.
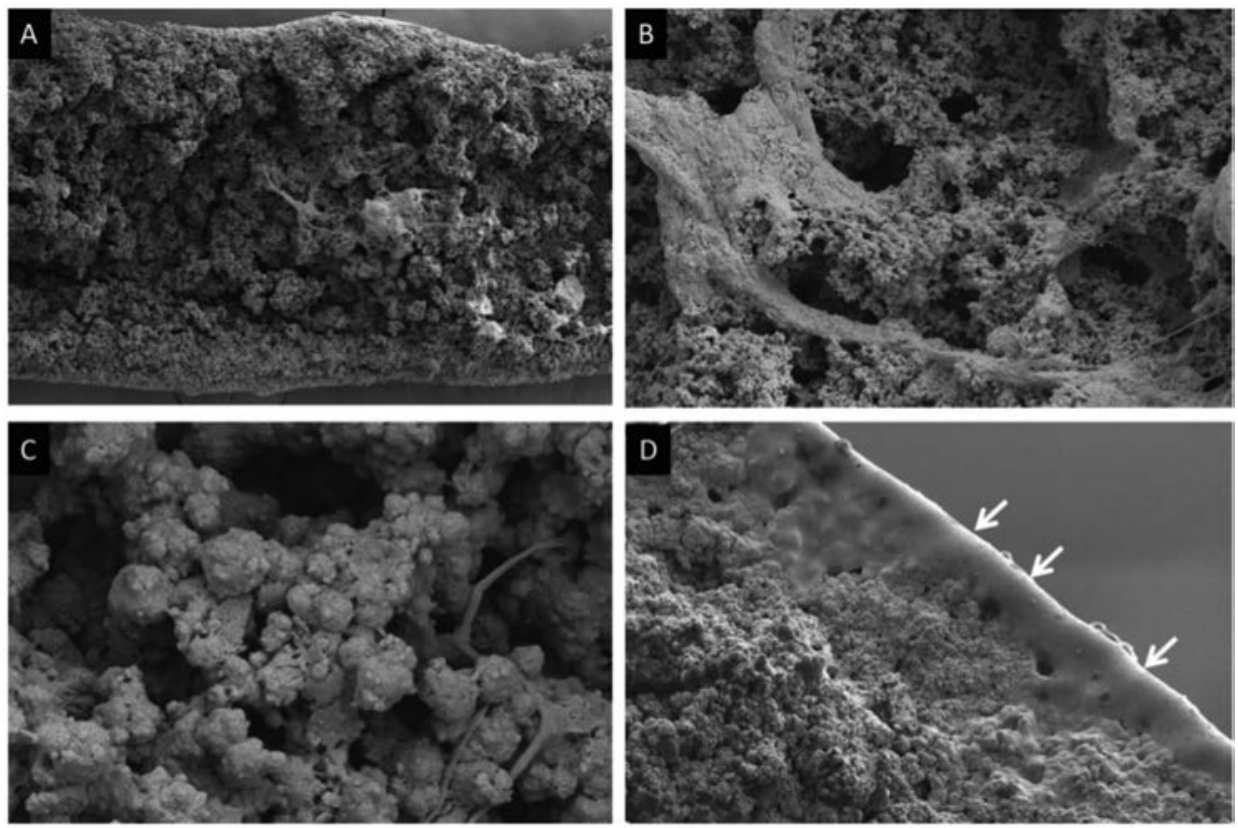

Figure 3 Electron micrograph showing intraluminal blood clots found within a catheter at magnifications of $(A) 350 X$, (B) 3,000X, and (C) 30,000X. (D) The clot is suspected to be propagated on a biofilm surface found at the inner membrane of the catheter 
Thrombosis can be further divided into 2 types;

1. Acute right-sided venous thrombosis, especially right atrial thrombosis, which is a rare but life-threatening complication possibly leading to pulmonary embolism and cardiac arrest. $^{32}$

2. Chronic central venous thrombosis, which is usually unrecognized and when left untreated may progress to extensive obstruction of the superior vena cava. ${ }^{33}$

Carefully following maintenance guidelines for the TIVADs, particularly saline and heparin flushing of the ports, can prevent this complication. Prophylactic urokinase has been studied in the management of long-term venous access devices in children, and one study found that urokinase administration every 2 weeks significantly affected the rate of occlusive events in ports and tunneled catheters and of infectious events in external catheters as compared to heparin administration. ${ }^{34}$ Although further analysis is needed, our experience in Songklanagarind Hospital indicates that flushing a CVC with urokinase every 1-2 months reduces the rate of occlusion-associated premature removal.

\section{Surgical approach to central venous access in potentially difficult cases}

In a patient with a history of long term CVL use who may experience multiple venous access, an evaluation of central veins is important to determine the appropriate site of venous approach. In such cases, the initial evaluation is usually performed using Doppler ultrasonography, which is generally used to check the 6 major accessible veins (the bilateral internal jugular, subclavian, and femoralexternal iliac veins). With an aim to evaluate the 'loss of accessibility', venography is recommended as a part of the preoperative workup (Table 3 ). In low risk (class I) patients, ultrasonography alone is sufficient. In moderate risk (class II) patients, a venography can be considered as a part of the work-up, but it is not universally indicated. In high risk (class III) patients, venography is recommended. A venography is the only approach to identify unconventional central access in the situation of end-staged central venous access (class IV patients). Recommendations for venography are individualized to each patient, taking into consideration that venography in small infants is associated with higher complication rates. ${ }^{35}$ Apart from conventional contrast venography under fluoroscopy, magnetic resonance venography can be an alternative choice of venography.

Table 3 Classification and recommendations for angiographic evaluation for vascular access using data from 6-vessel screening by Doppler ultrasonography ${ }^{35}$

\begin{tabular}{lll}
\hline Class & Vessel status & Venography \\
\hline I & No thrombosed vessels & Not necessary \\
II & One thrombosed vessel or risk factor of hypercoagulable state & Should be considered \\
III & Multiple thrombosed vessels & Recommended \\
IV & All vessels thrombosed & Mandatory \\
\hline
\end{tabular}




\section{Management of end-stage central venous access in children}

Permanent central venous use is a life-line in children with $\mathrm{PN}-$ dependent chronic intestinal failure. ${ }^{10}$ CVC maintenance can be complicated by recurrent episodes of line sepsis, and multiple replacements of the catheter can eventually lead to venous thrombosis. ${ }^{36}$ The lifetime of a catheter depends on insertion technique and sterility. Also important are catheter care, infection, thrombosis, and mechanical wear with repeated use. A Hickman-type catheter normally lasts more than 18 months, although the external portion of the catheter may break after several months of clamping, and cuffs and ports can potentially erode through the skin. Port membranes deteriorate as a result of repetitive punctures (manufacturers state 1,000 \pm 200 punctures depending on needle gauge used). ${ }^{37}$ Approximately $10.0 \%$ of intestinal-failure patients have difficulty in placement of a CVC and require an alternative technique to reestablish central venous access. $^{38}$ The clinical diagnosis rate of thrombosis associated with PN has been reported at around $10.0 \%$ to $20.0 \%$. However, in cases where a venography was used to diagnose the presence of thrombosis in the SVC, the incidence rose to $40.0 \%$ to $60.0 \%$. $^{39}$ This complication ranges from simple catheter occlusion to severe SVC and IVC obstruction. These have been described in association with right atrial thrombosis, pulmonary embolism, and Budd-Chiari Syndrome. ${ }^{39}$

End-stage central venous access is defined as a critical restriction in the patency of the SVC or major channels draining into it with or without inferior vena cava occlusion, resulting in the inability to secure central venous access using conventional sites or techniques. ${ }^{10}$ (Figure 4)

Options for the treatment of obstructions of the venous access include chemical or mechanical thrombolysis. Chemical thrombolysis relies on the use of thrombolytic agents, normally rTPA, which may allow avoidance of catheter replacement if successful. Thrombolytic therapy is normally safe and efficient for types 1-2 thrombosis, although it may potentially increase the risk of hemorrhage. The placement of a stent and the endovascular repositioning of a catheter without catheter removal after thrombosis of a vein in adults has also been described. ${ }^{40}$ However, long-term complications of stents, such as migration, stenosis, and thrombosis, may occur. Alternative sites for CVC placement (such as transhepatic, translumbar, or intercostal) are feasible, but all of these options require an invasive surgical approach in most cases and are not easily performed in small children. ${ }^{41}$ Interventional recanalization of the thrombosed vein is an other option that requires endovascular techniques.

When the traditional access sites at the internal jugular or subclavian veins are not feasible due to thrombosis, alternative access sites that can be considered in sequence include:

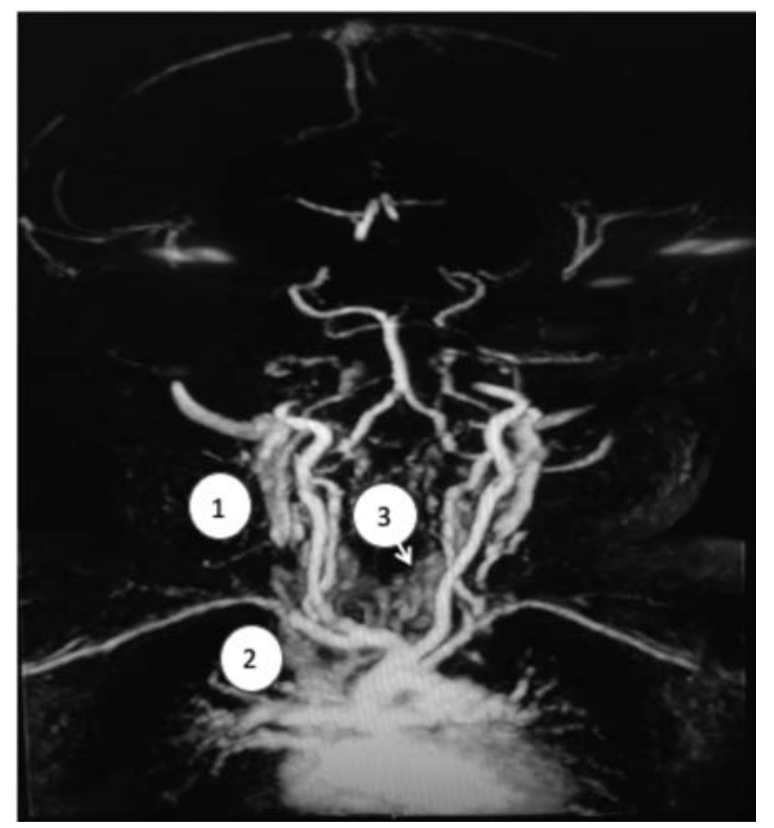

Figure $4 \mathrm{~A}$ magnetic resonance angiography of the neck veins in a 4-year-old female with intestinal failure who had end-stage central venous access. Note the severe thrombosis of the jugular vein (number 1), the subclavian and superior vena cava (number 2) and multiple collateral veins (number 3 ). 


\section{Access through a chest vein or a veins in the} lower part of the body

Multiple permanent venous catheters inserted in the internal jugular veins or subclavian veins might result in bilateral jugular or subclavian venous occlusion. Occlusion of some brachiocephalic veins and SVC might also occur. Compensation by collateral venous drainage takes place to prevent SVC syndrome and it provide potential routes of access. The selected target vein should be superficial, without intervening structures such as muscle or arteries as verified by fluoroscopic and/or sonographic evaluation. ${ }^{12}$

Possible collateral venous drainage sites include enlarging mediastinal, chest wall, paraspinal, or azygos venous pathways, which should be considered before proceeding to the femoral veins, IVC, or the hepatic veins. In our experience, these collateral veins are among the best alternative choices when the jugular and subclavian veins have closed. The right posterior intrapleural thoracotomy offers access to the azygos vein system, superior vena cava, and right atrium for central venous cannulation under direct vision. In children with no central vein available, cannulation of the intercostal veins is advantageous because the presence of many intercostal veins, all with equal access to the azygos system (Figure 5), allows multiple cannulations. ${ }^{7}$ There are only 4 reports in the literature about the use of an intercostal vein for prolonged central venous cannulation and PN. Malt and Kempster ${ }^{13}$ first described the direct insertion of a Hickman catheter into the azygos vein and SVC cannulation through an intrapleural thoracotomy. Pokorny et al. ${ }^{42}$ described this procedure via an extrapleural thoracotomy in two pediatric patients. Newman et al. ${ }^{43}$ and Cronen et al. ${ }^{44}$ applied intercostal vein cannulation through a small posterior intercostal incision without a thoracotomy.

\section{Access through unusual veins}

In cases that all options for central catheter insertion at the chest wall are exhausted, the remaining alternatives are all associated with an increased risk of long-term complications such as occlusion or infection.
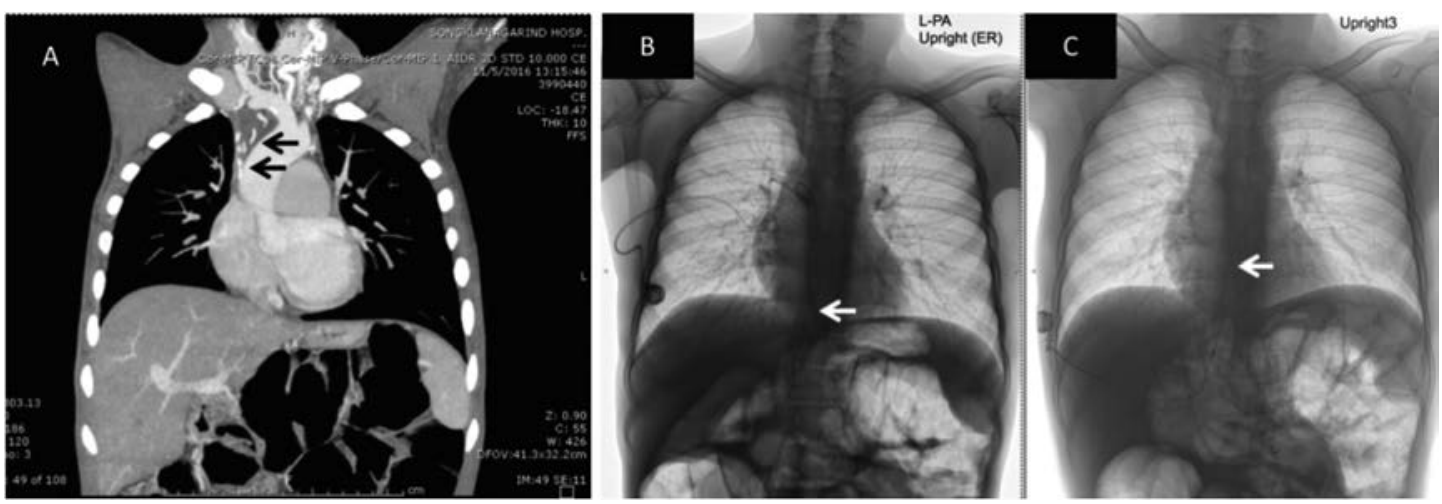

Figure 5 Illustration of a case with congenital intestinal failure who had had multiple venous catheterizations for parenteral nutrition since his infantile period. (A): A computerized tomography scan showing occlusion of the superior vena cava caused by thrombosis with multiple collaterals (black arrows). (B) and (C): Accessing the inferior vena cava via an open intercostal-azygos route and percutaneous lumbar vein cannulation (tip of the white arrow) (courtesy of Dr. Kittipitch Bannangkoon and Dr. Keerati Hongsakul, Department of Radiology, Songklanagarind Hospital) 
The first choices after the chest veins have been ruled out are a femoral route or direct access of the IVC via a translumbar approach. ${ }^{12}$ The direct puncture of the IVC is an option for placement of permanent central venous access. This procedure is more technically challenging and time-consuming than a chest vein. ${ }^{12}$ Post-procedural complications or catheter malfunctions occur with greater frequency when using this route compared with a permanent catheter placed in a chest vein. Relatively more difficult to immobilize the implanted system with proper dressing and higher chance of contamination may explain shorter device use.

There are a few reports of unusual methods of venous access in pediatric patients in the English literature. In 1989, Robards et al. reported one case of percutaneous translumbar IVC central line placement in a critically ill child. The patient was a 2-year-old male who had vena cava thrombosis and fungal sepsis. The patient failed urokinase therapy for the thrombosis and he was not a candidate for direct right atrial cannulation because of risk from multiple previous thoracotomies. Percutaneous translumbar access to the $L 3$ vertebral body was performed. The tip was in the IVC at the level of the hepatic vein. The catheter was successfully used for several months after which time the child died from cardiac disease. ${ }^{45}$ In 1980, Donahoe and $\mathrm{Kim}^{14}$ described the use of the inferior epigastric vein in neonates in whom no other access was available.

A useful alternative route is the placement of a catheter via the gonadal vein to the right atrium using an open retroperitoneal approach. ${ }^{7}$ The advantage of this technique is the direct exposure of the vein before catheterization. In children who have extensive thrombosis of the iliofemoral system and lower IVC, the favorable venous drainage anatomy of the gonadal vein bypasses the occlusion. The gonadal vein is dilated, making identification and cannulation easier. ${ }^{46}$ The right gonadal vein was chosen because it drained directly into the IVC.
Although the hepatic veins are accessible by a transhepatic puncture under ultrasonographic guidance, the use of percutaneous transhepatic veins placement is associated with a high rate of postprocedural complications, such as catheter malfunction and increased frequency of required catheter exchanges. A common complication is the displacement of the catheter tip from its optimal location in the right atrium resulting from excursion of the liver during inhalation and exhalation. Stavropoulos et al., in a series of 36 catheters accessed through a hepatic vein, found a high rate of catheter occlusion, measuring 2.4 per 100 catheter days. The rate of line sepsis was 0.22 per 100 catheter days. ${ }^{47}$ Boe et al. followed 92 transhepatic central venous catheters placed in 54 pediatric patients (median age 5.7 months). The complications and their rates per 1,000 catheter days included catheter dysfunction (14.8), dislodgement (8.8), systemic infection (5.1) and thrombosis (4.2). The use of polyurethane catheters and catheter duration at least 21 days were the 2 main factors associated with increased transhepatic central venous catheter complications. ${ }^{48}$ Marshall et al. reviewed 12 congenital heart disease patients who had one or more transhepatic venous catheters. They found that the transhepatic venous lines had superior duration of service without increased thrombosis, thrombolytic use, or insertion site complications relative to central venous lines despite a higher infection rate. ${ }^{49}$

\section{Surgical techniques used in difficult venous}

\section{access}

An interventional method is the first choice to access central venous catheterization or to correct the complications from central catheterization with many techniques such as angioplasty, fibrinolytic or thrombolytic therapy or endovascular management, as described earlier. However, open surgery can be an option for the management of end stage central venous access when 
intervention radiology fails to establish access. Alternative access techniques are:

\section{-Retrograde recanalization by the kissing catheters}

\section{technique}

Roessingh et al. reported two cases of children younger than 1 year who were dependent on their CVCs for PN. They both developed chronic extensive obstructions of the right and left brachiocephalic veins with SVC syndrome. A retrograde recanalization of the SVCs was successfully achieved using pathways created under general anesthesia from the femoral vein to the right thyroid vein and the right subclavian vein and axillary veins in the other patient. ${ }^{41}$ The authors called the technique 'kissing catheters'.

\section{-Direct right atrial catheterization}

Oram-Smith et al. reported the first case of a patient with severe nutritional deficiency and no adequate access to the central venous system for total parenteral nutrition. Operative placement of a catheter directly into the right atrium allowed adequate nutritional support. ${ }^{15}$ Atrial access can be established by either open surgery or percutaneous puncture under digital subtraction fluoroscopy.

\section{-Arteriovenous fistula (AVF)}

An alternative management is a surgically created AVF. ${ }^{50}$ These fistulas are usually constructed in the forearm. The main problem in these fistulas is the risk of occlusion. Fistulas are reported to be safer and more valuable alternatives than catheters for adult patients requiring $\mathrm{PN}$. In children, AVFs have been reported in patients with hemophilia and requiring hemodialysis. ${ }^{5}$ Because of the small vein size in children, the upper arm is usually chosen for an AVF. No reports are available about pediatric patients receiving PN via an arteriovenous fistula. ${ }^{52}$

\section{Conclusion}

Difficult venous access is an end-stage problem occurring in pediatric patients with repeated venous catheterization. The problem can be reduced by careful catheter insertion at the first catheters and proper maintenance by a multidisciplinary team (Figure 6). Protocolized care including routine patency check and prophylactic thrombolysis is advisable. In cases with end-stage venous pathology, extensive evaluation of venous anatomy and stepwise selection of an access route is recommended.

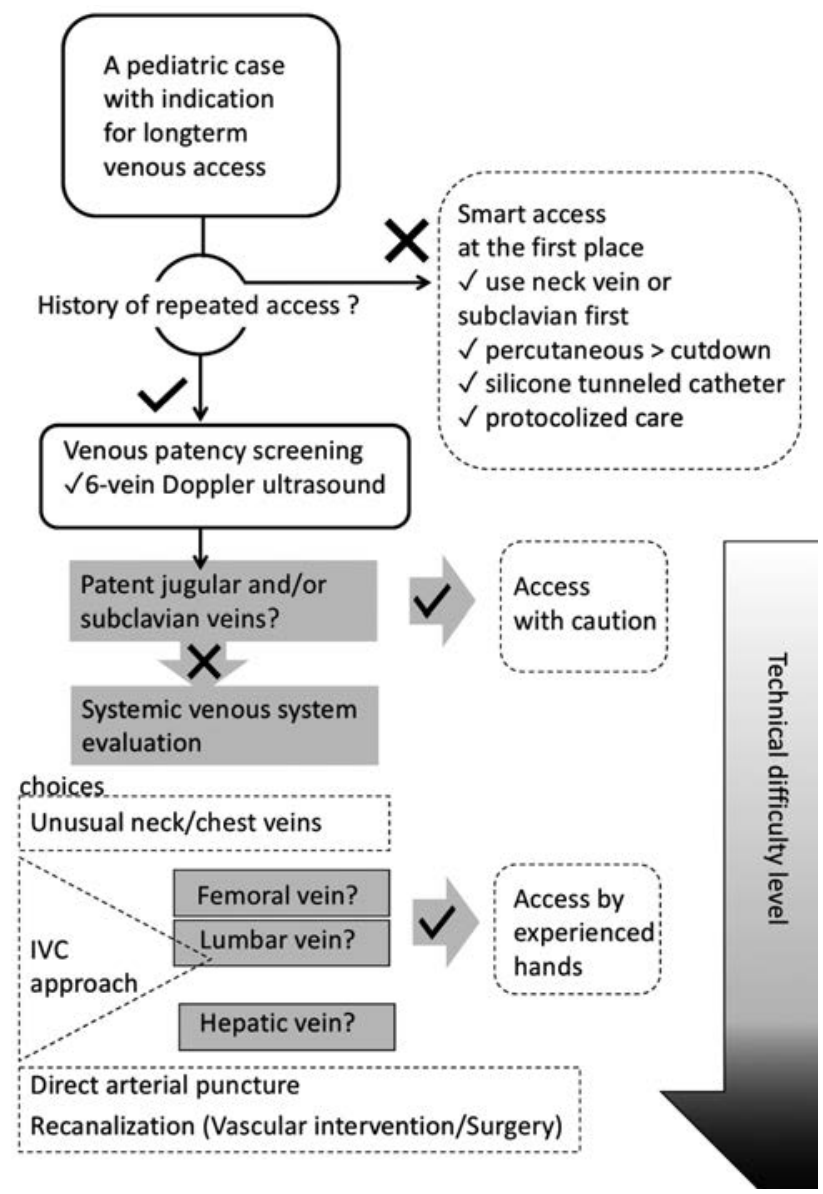

Figure 6 Algorithm for approaching a difficult central venous access in a pediatric patient who needs long-term central venous access. 'Smart access' or access with great caution at the first time is among the keys upstream elements. 


\section{Acknowledgement}

Dave Patterson edited the English language in the manuscript. Wisthawash Tangon produced the graphical illustrations.

\section{References}

1. Stovroff $M$, Teague WG. Intravenous access in infants and children. Pediatr Clin North Am 1998;45:1373-93.

2. Wesley JR. Permanent central venous access devices. Semin Pediatr Surg 1992;1:188-201.

3. Scott-Warren VL, Morley RB. Paediatric vascular access. BJA Education 2015;15:199-206.

4. Faraj W, Zahal A, El-Beyrouthy O, Kutoubi A. Complete catheter disconnection and migration of an implantable venous access device: the disconnected cap sign. Ann Vasc Surge 2010;24:11-692.e11-5

5. Zaghal A, Khalife M, Mukherji D, El Majzoub N, Shamseddine A, Hoballah $J$, et al. Update on totally implantable venous access devices. Surg Oncol 2012;21:207-15.

6. Mughal MM. Complications of intravenous feeding catheters. Br J Surg 1989;76:15-21.

7. Saleh HM, Abdelaziz AS, Hefnawy E, Mansour O. Alternate routes for children with difficult central venous access. Acta Chir Belg 2008;108:563-8.

8. Rupp SM, Apfelbaum JL, Blitt C, Caplan RA, Connis RT, Domino KB, et al. Practice guidelines for central venous access. Anesthesiology 2012;116:539-73.

9. Othersen HB Jr, Hebra HA, Chessman KH. Central lines in parenteral nutrition. In: Pediatric parenteral nutrition. New York: Chapman \& Hall; 1997;p.254-71.

10. Rodrigues AF, van Mourik ID, Sharif K, Barron DJ, de Giovanni $\mathrm{JV}$, Bennett J, et al. Management of end-stage central venous access in children referred for possible small bowel transplantation. J Pediatr Gastroenterol Nutr 2006;42:42733.

11. Mestrovic J, Kovacevic T, Ercegovic I, Polic B, Stricevic L, Omazic A, et al. Use of central venous catheter in children. Signa Vitae 2006;1:20-4.

12. Lorenz JM. Unconventional venous access techniques. Semin Intervent Radiol 2006;23:279-86.

13. Malt RA, Kempster M. Direct azygos vein and superior vena cava cannulation for parenteral nutrition. JPEN J Parenter Enteral Nutr 1983;7:580-1.

14. Donahoe PK, Kim SH. The inferior epigastric vein as an alternate site for central venous hyperalimentation. J Pediatr Surg 1980;15:737-8.

15. Oram-smith JC, Mullen JL, Harken AH, Fitts WTJR. Direct right atrial catheterization for total parenteral nutrition. Surgery 1978;83:274-6.

16. OpenStax College. Anatomy \& physiology [monograph on the Internet]. Texas: OpenStax College, Rice University; 2013 [cited 2017 May 20]. Available from: http://cnx.org/content/ col11496/1.6/

17. Hamzeh RK, Donan S, Shah S, Levi DS, Moore JW. "Wiretarget" technique for precise vascular access. Tex Heart Inst J 2009;36:321-6.

18. Carlo ID, Biffi R, Niederhuber J. Totally implantable venous access devices management in mid- and long-term clinical setting. New York: Springer; 2011.

19. O’Grady NP, Alexander M, Dellinger EP, Gerberding JL, Heard SO, Maki DG, et al. Guidelines for the prevention of intravascular catheter-related infections. Centers for disease control and prevention. MMWR Recomm Rep 2002; 51:1-29.

20. Kock HJ, Pietsh M, Krause U, Wilke H, Eigler FW. Implantable vascular access systems: experience in 1,500 patients with totally implanted central venous port systems. World J Surg 1998;22:12-6.

21. Maki DG KD, Crnich CJ. The risk of bloodstream infection in adults with different intravascular devices: a systematic review of 200 published prospective studies. Mayo Clinic Proc 2006;81:1159-71.

22. Garnacho-Montero J, Aldabo-Pallas T, Palomar-Martınez M, Valles J, Almirante B, Garces R, et al. Risk factors and prognosis of catheter-related bloodstream infection in critically ill patients: a multicenter study. Intensive Care Med 2008;34: 2185-93.

23. Deshpande KS, Hatem C, Ulrich HL, Currie BP, Aldrich TK, Bryan-Brown CW, et al. The incidence of infectious complications of central venous catheters at the subclavian, internal jugular, and femoral sites in an intensive care unit population. Crit Care Med 2005;33:13-20.

24. East D, Jocoby K. The effect of a nursing staff education 
program on compliance with central line care policy in the cardiac intensive care unit. Pediatr Nurs 2005;31:182-4.

25. Pronovost P, Needham D, Berenholtz S, Sinopoli D, Chu H, Cosgrove S, et al. An intervention to decrease catheter-related bloodstream infections in the ICU. N Eng J Med 2006;355: 2725-32.

26. Mimoz O, Villeminey S, Ragot S, Dahyot-Fizelier C, Laksiri L, Petitpas F, et al. Chlorhexidine-based antiseptic solution vs alcohol-based povidone-iodine for central venous catheter care. Arch Intern Med 2007;167:2066-72.

27. Journeycake JM, Buchanan GR. Thrombotic complications of central venous catheters in children. Curr Opin Hematol 2003;10:369-74.

28. Machado JD, Suen VM, Figueiredo JF, Marchini JS. Biofilms, infection, and parenteral nutrition therapy. JPEN J Parenter Enteral Nutr 2009;33:397-403

29. Starkhammar H, Bengtsson M, Morales O. Fibrin sleeve formation after long term brachial catheterisation with an implantable port device. A prospective venographic study. Eur J Surg 1992;158:481-4.

30. Timoney JP, Malkin MG, Leone DM, Groeger JS, Heaney ML, Keefe DL, et al. Safe and cost effective use of alteplase for the clearance of occluded central venous access devices. J Clin Oncol 2002;20:1918-22.

31. Whigham CJ, Lindsey JI, Goodman CJ, Fisher RG. Venous port salvage utilizing low dose tPA. Cardiovasc Intervent Radiol 2002;25:513-6.

32. Kingdon EJ, Holt SG, Davar J, Pennell D, Bailod RA, Burns A, et al. Atrial, thrombus, and central venous dialysis catheters. Am J Kidney Dis 2001;38:631-9.

33. Kroger K, Grutte R, Rudofsky G, Fink H, Niebel W. Followup after port-a-cath-induced thrombosis. J Clin Oncol 2002 20:2605-6.

34. Chen CY, Liu CC, Sun WZ. Evidence-based review on catheter-related thrombosis of the implantable venous access device. Tzu Chi Med J 2007;19:207-19.

35. Selvaggi G, Gyamifi A, Kato T, Gelman B, Aggarwal S, Begliomini B, et al. Analysis of vascular access in intestinal transplant recipients using the Miami classification from the VIIlth International Small Bowel Transplant Symposium. Transplantation 2005;79:1639-43.

36. Kaufman SS, Atkison JB, Bianchi A, Goulet OJ, Grant D,
Langnas AN, et al. Indications for pediatric intestinal transplantation: a position paper of the American Society of Transplantation. Pediatr Transplant 2001;5:80-7.

37. Galloway S, Bodenham A. Long-term central venous access. $\mathrm{Br} J$ Anesth 2004;92:722-34.

38. Gupte GL, Protheroes S, McKiernan P, Murphy S, Booth I, Kelly D, et al. Improvements in outcome of chronic intestinal failure in the UK 1989-2002. J Paediatr Gastroenterol Hepatol Nutr 2004;39:40.

39. Mulvihill SJ, Fonkalsrud EW. Complications of superior versus inferior vena cava occlusion in infants receiving central total parenteral nutrition. J Pediatr Surg 1984;19:752.

40. Qanadli SD, Mesurolle B, Sissakian JF, Chagnon S, Lacombe $\mathrm{P}$, et al. Implanted central venous catheter-related acute superior vena cava syndrome: management by metallic stent and endovascular repositioning of the catheter tip. Eur Radiol 2000;10:1329-31.

41. de Buys roessingh AS, portier-Marret N, Terciera S, Qanadli SD, Joseph JM. Qanadlib, Jean-Marc Josepha. Combined endovascular and surgical recanalization after central venous catheter-related obstructions. J Pediatric Surg 2008;43:E21-4.

42. Pokorny WJ, McGil CW, Haberg FJ. The use of the azygos vein for central catheter insertion. Surgery 1985;97:362.

43. Newman BM, Cooney DR, Karp MP, Jewett TC JR. The intercostal vein: an alternate route for central venous alimentation. J Pediatr Surg 1983;18:732-3.

44. Cronen PW, Brown G, Crowley R. Use of an intercostal and azygos vein for central hyperalimentation. JPEN J Parenter Enteral Nutr 1984;8:590

45. Azizkhan RG, Taylor LA, Jaques PF, Mauro MA, Lacey SR. Percutaneous translumbar and transhepatic inferior vena caval catheters for prolonged vascular access in children. J Pediatr Surg 1992;19:165-9.

46. Chang MY, Morris JB. Long-term central venous access through the ovarian vein. J Parent Ent Nutr 1997;21:235-7.

47. Smith TP, Ryan JM, Reddan DN. Transhepatic catheter access for hemodialysis. Radiology 2004;232:246-51.

48. Boe BA, Zampi JD, Yu S, Donohue JE, Aiyagarri R. Transhepatic central venous catheters in pediatric patients with congenital heart disease. Pediatr Crit Care Med 2015;16: 726-32.

49. Marshall AM, Danford DA, Curzon CL, Anderson V, Delaney 
JW. Traditional long-term central venous catheters versus transhepatic venous catheters in infants and young children. Pediatr Crit Care Med 2017;18:944-8.

50. Versleijen MW, Huisman-de-waal GJ, Kock MC, Elferink $A J$, van Rossum LG, Feuth $T$, et al. Arteriovenous fistulae as an alternative to central venous catheters for delivery of long-term home parenteral nutrition. Gastroenterology 2009;136:1577-84.
51. Chand DH, Valentini RP, Kamil ES. Hemodialysis vascular access options in pediatrics: considerations for patients and practitioners. Pediatr Nephrol 2009;24:1121-8.

52. McCarthy WJ, Valentino LA, Bonilla AS, Goncharova I, Taylor A, Pooley TA, et al. Arteriovenous fistula for long-term venous access for boys with hemophilia. J Vasc Surg 2007; 45:986-90. 